\title{
Successful fertilization after superovulation and laparoscopic intrauterine insemination of the brushtail possum, Trichosurus vulpecula, and tammar wallaby, Macropus eugenii
}

\author{
F. C. Molinia ${ }^{\mathrm{I}}$, R. J. Gibson ${ }^{1}$, A. M. Brown ${ }^{1}$, A. M. Glazier ${ }^{2}$ and \\ J. C. Rodger ${ }^{3}$ \\ Cooperative Research Centre for Conservation and Management of Marsupials at: \\ ${ }^{1}$ Department of Biological Sciences, University of Newcastle, Newcastle, NSW 2308, Australia; ${ }^{2}$ Landcare \\ Research, PO Box 69, Lincoln 8152, New Zealand; and ${ }^{3}$ School of Biological Sciences, Macquarie University, \\ Sydney, NSW 2109, Australia
}

\begin{abstract}
Fertilization has been achieved in superovulated brushtail possums and tammar wallabies after laparoscopic intrauterine artificial insemination. Various superovulation protocols and insemination times were examined but a maximum of 2-5 eggs including 1-2 embryos per possum were recovered. The female possums were superovulated by treatment with 15 iu pregnant mares' serum gonadotrophin and then either GnRH $(4 \times 50 \mu \mathrm{g}$, at intervals of $90 \mathrm{~min}$ ) or $4 \mathrm{mg} \mathrm{LH}, 3$ days later. Inseminations were performed within $6 \mathrm{~h}$ before or $4-10 \mathrm{~h}$ after (pregnant mares' serum gonadotrophin-GnRH group only) the expected onset of ovulation using epididymal spermatozoa. Superovulation in wallabies was achieved by treatment with FSH ( $8 \times 6 \mathrm{mg}$, at intervals of $12 \mathrm{~h}$ for 4 days) followed by $4 \mathrm{mg}$ LH on day 5. Inseminations were performed $4-6 \mathrm{~h}$ before the expected onset of ovulation using ejaculated spermatozoa, which resulted in the recovery of 7-8 eggs including 3-4 embryos per female. All embryos recovered were from possums and wallabies examined $1-2$ days after insemination and included fertilized eggs, two-cell and four-cell embryos. Motile spermatozoa were recovered from the oviducts and uteri but only immotile spermatozoa were found in the vaginal complex. Five to thirty per cent of spermatozoa recovered from the oviducts of possums examined 2-6 h after insemination had thumbtack morphology, which is thought to be correlated with capacitation. Although embryo yields per female were low, this study has established that intrauterine artificial insemination after superovulation is a feasible assisted breeding strategy for marsupials with implications for species conservation and population control.
\end{abstract}

\section{Introduction}

Techniques for manipulating reproduction and productivity are well established in domestic species (Greenwald and Terranova, 1988) and have been developed for a number of other eutherian mammals mainly for application in conservation (Wildt et al., 1995). Only recently has work begun on developing practical artificial breeding technologies in marsupials (Rodger, 1990). Hormone-induced superovulation of monovular marsupials has been successfully achieved over the last decade. These techniques produce large numbers of mature ovulated oocytes but, as subsequent mating is unreliable, the embryo yield is poor (Hinds et al., 1996). If artificial insemination could be established for superovulated marsupials, it would be a powerful tool for basic research on marsupial gamete and embryo function and would provide a basis

Revised manuscript received 11 September 1997. for the development of assisted breeding strategies for the conservation of rare or endangered species.

Superovulation of the brushtail possum has been achieved after treatment with 10 iu pregnant mares' serum gonadotrophin (PMSG) followed 3 days later by synthetic gonadotrophin releasing hormone $(\mathrm{GnRH}: 3 \times 50 \mu \mathrm{g}$, at intervals of $90 \mathrm{~min}$ ) and results in the recovery of $8-24$ mature oocytes (Rodger and Mate, 1988). Using this protocol, Hayman and Rodger (1990) suggested that ovulation commenced about $24 \mathrm{~h}$ after the first GnRH treatment. Recently, a superovulation protocol has been developed for the tammar wallaby which yields large numbers of oocytes in both cyclic and noncyclic animals (Molinia et al., in press). An average of 7-13 mature ovulated oocytes was recovered from females treated with pig FSH for 4 consecutive days $(8 \times 6 \mathrm{mg}$, at intervals of $12 \mathrm{~h}$ ) and then $4 \mathrm{mg}$ pig LH on the fifth day. When this protocol was used, ovulation commenced about $36 \mathrm{~h}$ after $\mathrm{LH}$ administration. 
Artificial insemination in eutherian mammals is usually carried out non-surgically with the sperm sample deposited in the uterus from a cannula passed through the cervix and vagina. An exception to this is artificial insemination of ewes, in which the anatomy of the cervix makes penetration with an insemination pipette difficult. Laparoscope-guided surgical intrauterine insemination was developed to overcome this problem (Evans, 1988). In marsupials, the external opening leads not to a simple tubular vagina and cervix, but to the urogenital sinus (UGS) which leads to the vaginal complex and bladder. The vaginal complex is composed of two lateral arms and a central cul-de-sac which in most marsupials is closed except when it connects with the UGS to form the median birth canal at parturition. Thus, access to the cervices requires negotiation of the UGS and lateral vaginae. Parous macropods have a permanent median birth canal, suggesting that a more direct route to the cervices is feasible. However, attempts to visualize and access the cervices via the birth canal with the aid of a laparoscope have so far proved unsuccessful in tammar wallabies (F. C. Molinia and J. C. Rodger, unpublished). Since a laparoscopic procedure has already been developed for the purpose of ovarian examination in tammar wallabies (Rodger et al., 1993), it was decided to examine whether laparoscopeguided artificial insemination into the uterus (IUAI) could be used in marsupials.

The primary aim of the present study was to use current superovulation protocols in conjunction with laparoscopic IUAI to achieve conception in the common brushtail possum and tammar wallaby. A secondary aim was to make observations on the status of spermatozoa recovered from the female tract after insemination.

\section{Materials and Methods}

\section{Animals}

Brushtail possums (Trichosurus vulpecula) were captured in box traps in the North Canterbury region of New Zealand and transferred to the Landcare Research Animal Facility at Rangiora. Animals were weighed and separate sexes were moved to either individual cages or into pens of $8-16 \mathrm{~m}^{2}$. The animals were maintained on a diet of cereal pellets supplemented with fruit and vegetables and their food and water requirements were attended to each day. Tammar wallabies (Macropus engenii) were from the breeding colony of the University of Newcastle. Animals were kept in open grassy yards at the University of Newcastle Central Animal House. The animals were maintained on a diet of kangaroo pellets, lucerne hay and mixed grasses, and their food and water requirements were attended to each day. Experiments were approved by the Animal Ethics Committee of Manaaki Whenua Landcare Research and the University of Newcastle Animal Care and Ethics Committee. Use of protected species was approved by the NSW Parks and Wildlife Service.

\section{Superovulation}

Before laparoscopic IUAI, two PMSG-GnRH and two PMSG-LH hormone treatments were used for superovulation of female possums while a FSH-LH protocol was used for superovulation of female wallabies (Table I). Only female possums and wallabies $>2 \mathrm{~kg}$ and $>4 \mathrm{~kg}$, respectively, with evidence of a well developed pouch were used. For the possums, all PMSG (Folligon; Intervet, Oss) treatments (10 or $15 \mathrm{iu})$ were single i.m. injections followed 3 days later by $4 \times 50 \mu \mathrm{g}$ i.m. injections of GnRH (Fertagyl; Intervet) at intervals of $90 \mathrm{~min}$, or a single i.m. injection of 2.5 or $4 \mathrm{mg} \mathrm{LH}$ (Lutropin-V; Vetrepharm, London, Ontario). For the wallabies, i.m. injections of $6 \mathrm{mg}$ FSH (Folltropin-V; Vetrepharm, Essendon, Victoria) were administered twice a day (at intervals of $12 \mathrm{~h}$ ) for 4 consecutive days followed by a single s.c. injection of $4 \mathrm{mg} \mathrm{LH}$ on day 5 .

\section{Collection and processing of semen}

During the breeding season, semen was collected by electroejaculation (Mate and Rodger, 1991) from mature male possums $>2.5 \mathrm{~kg}$ or wallabies $>5 \mathrm{~kg}$ under general anaesthesia induced by halothane (Rhône Mérieux, West Footscray, Victoria) or fluothane (Zeneca, Macclesfield, Cheshire) by mask $\left(2.5-3.5 \%, 2 \mathrm{I} \mathrm{O}_{2} \mathrm{~min}^{-1}\right)$. At least 7 days separated successive electroejaculations from any one animal. Wallaby spermatozoa were washed by swim-up into PBS $(0.01 \mathrm{~mol}$ phosphate buffer $\mathrm{l}^{-1}$, $138 \mathrm{mmol}$ sodium chloride $1^{-1}, 2.7 \mathrm{mmol}$ potassium chloride $\mathrm{I}^{-\mathrm{I}}, \mathrm{pH} 7.4$ at $25^{\circ} \mathrm{C}$ ) from the coagulated ejaculate as described by Sistina et al. (1993). Possum semen, which does not coagulate, was used unwashed. Outside the breeding season, epididymal spermatozoa were collected from the cauda epididymides of males killed by barbiturate overdose. Males were anaesthetized by $\mathrm{CO}_{2}: \mathrm{O}_{2}\left(31: 11 \mathrm{~min}^{-1}\right)$, and then killed with a single intracardiac injection of sodium pentobarbitone (Pentobarb; Chemstock Animal Health, Christchurch) at a dose rate of $125 \mathrm{mg} \mathrm{kg}^{-1}$. The cauda epididymis was separated from the testis, then the surface of the tissue was lacerated with a sharp blade and suspended in PBS to permit release of spermatozoa. Motility and concentration of electroejaculated or epididymal spermatozoa were assessed using phase-contrast microscopy and a haemocytometer as described by Rodger et al. (1991), respectively. Samples of spermatozoa were diluted in PBS to a concentration of $1 \times 10^{7}$ motile spermatozoa $\mathrm{ml}^{-1}$ and used within $30 \mathrm{~min}$ of collection. Since marsupial spermatozoa are resistant to cold-shock (Rodger and White, 1978), possum or wallaby spermatozoa were alternatively stored at $4^{\circ} \mathrm{C}$ for up to $6 \mathrm{~h}$, and then warmed to room temperature before use.

\section{Laparoscopic intrauterine arti Acial insemination}

Epididymal or electroejaculated spermatozoa were used for inseminations, which were performed before and after the expected onset of ovulation (Table 1).

Anaesthesia was induced by an i.m. injection of tiletamine chlorhydrate $\left(50 \mathrm{mg} \mathrm{ml}^{-1}\right.$ ) and zolazepam chlorhydrate (50 $\mathrm{mg} \mathrm{ml}^{-1}$ ) (Zoletil 100; Virbac, Peakhurst, NSW or Techvet, Otahuhu, Auckland) at a dose of $30 \mathrm{mg} \mathrm{kg}^{-1}$ after a pre-med i.m. injection of $0.1 \mathrm{mg} \mathrm{kg}^{-1}$ atropine (Apex Laboratories, St Marys, NSW or Techvet). Once anaesthetized (after approximately 5-10 $\mathrm{min}$ ) the animals were restrained on their 
backs with the head below the abdomen at an angle of approximately $30^{\circ}$ to minimize the danger of accidentally damaging organs and to improve visualization of the contents of the pelvic cavity.

Laparoscopy was performed in the wallaby as described by Rodger et al. (1993). Diluted spermatozoa $(0.4 \mathrm{ml}$ containing approximately $4 \times 10^{6}$ motile spermatozoa) were loaded into plastic insemination pipettes (consisting of a $30 \mathrm{~cm} \times 5 \mathrm{~mm}$ plastic pipette and 25 gauge $\times 6 \mathrm{~mm}$ needle; Kevin Gobby Surgical Equipment, Balcatta, WA) using a $1.0 \mathrm{ml}$ syringe. Under direct laparoscopic observation, spermatozoa were inseminated into both uteri $(0.2 \mathrm{ml}$ per uterus) using the method described for the ewe by Evans and Maxwell (1987). Laparoscopic instruments were removed and the incision sites were sutured. An antibiotic powder or spray was administered to these sites at the end of the surgery. The interval from anaesthesia to laparoscopy (from induction of anaesthesia to suturing) was $15-30 \mathrm{~min}$.

\section{Examination of reproductive tracts}

Female possums and wallabies were killed by barbiturate overdose up to 2 days after IUAI to assess ovarian response to the superovulation protocol and to evaluate the spermatozoa and eggs recovered from the reproductive tract (Table 1 ). Animals were not examined after 2 days in the present study because in preliminary studies, $>60 \%$ of embryos recovered from superovulated possums killed from 4 days after IUAI had degenerated. Female possums were killed as detailed above for male possums. Female wallabies were killed with a single i.v. injection of sodium pentobarbitone (Lethabarb; Virbac) into the tail vein at a dose rate of $100 \mathrm{mg} \mathrm{kg}^{-1}$. Reproductive tracts were removed and the ovaries separated for assessment of numbers of ovulation sites and remaining unovulated follicles ( $>2 \mathrm{~mm}$ ). Oviducts and uteri were flushed with $\mathrm{I}$ and $2 \mathrm{ml}$ of heparinized (12.5 iu ml ${ }^{-1}$ ) PBS, respectively, for spermatozoa and eggs. All eggs retrieved were stained with the DNAspecific dye Hoechst 33342 for $4-5 \mathrm{~min}$ (in $10 \mu \mathrm{g} \mathrm{ml}^{-1}$ in PBS; Sigma Chemical Company, St Louis, MO), and then washed in PBS before examination by fluorescence microscopy (Zeiss Axiovert 35 microscope). Eggs that showed pronuclei and two polar bodies after staining and two-cell and four-cell embryos were classed as fertilized. Evidence of spermatozoa in the flushes and in vaginal smears (prepared by smearing slides across the two cervices and central vagina) after microscopic examination under Hoffman modulation contrast (Zeiss Axiovert 35 microscope) was also recorded.

\section{Electron microscopy}

Fertilized eggs and embryos recovered from possums (as judged by fluorescence microscopy) were processed for electron microscopy to detect remnants of spermatozoa in the egg cytoplasm to confirm that they were successfully fertilized and not parthenogenetically activated. Embryos were fixed immediately in 2/3 Superfix (Zamboni and De Martino, 1967) at $\mathrm{pH} 7.6$ overnight at $4^{\circ} \mathrm{C}$ before storage in $0.1 \mathrm{~mol}$ cacodylate buffer $1^{-1}, \mathrm{pH} 7.4$ at room temperature (Mate et al., 1992). Post-fixation was in $1 \%(\mathrm{w} / \mathrm{v}) \mathrm{OsO}_{4}$ in $0.1 \mathrm{~mol}$ cacodylate buffer $\mathrm{l}^{-1}$ for $1 \mathrm{~h}$ at $4^{\circ} \mathrm{C}$. This was followed by washing in distilled water, dehydration and embedding in Spurr's resin. Ultrathin sections were placed on copper grids, stained with uranyl acetate and lead citrate and examined on a Joel CX-100 electron microscope.

\section{Statistical analyses}

Data from the ovarian assessments, egg and embryo recoveries of animals that responded to hormone treatment (that is, ovulated) are presented as mean values with range intervals. Comparison of treatment means was examined nonparametrically using a Kruskal-Wallis one-way ANOVA on ranks. Dunn's method was used for pairwise multiple comparison to determine which treatment groups were different. All these analyses were performed using SIGMASTAT ${ }^{\mathbf{R}}$ (Version 2.0 for Windows ${ }^{\text {(K) }}$ 95, 1985).

\section{Results}

\section{Ovarian response and embryo recovery}

The superovulation protocols examined in this study resulted in the recovery of multiple mature oocytes from the brushtail possum and tammar wallaby up to 2 days after laparoscopic IUAI (Table 1). The earliest time that an embryo was recovered was $20 \mathrm{~h}$ after IUAI. Often, fertilized eggs (pronuclei and two polar bodies), and two-cell and four-cell stage embryos were retrieved simultaneously from a single female possum (Fig. 1) or wallaby (Fig. 2) but only from animals killed 2 days after IUAI. Fertilized eggs were recovered from the oviducts, whereas two- and four-cell embryos were recovered from the uteri.

Possum. For females primed with I5 iu PMSG, 90-100\% ovulated after treatment with $\mathrm{GnRH}$ or $4 \mathrm{mg} \mathrm{LH}$, while $73-82 \%$ ovulated if a lower dose of $\mathrm{LH}$ ( $2.5 \mathrm{mg}$ ) was used. This response was far better than for the group primed with 10 iu PMSG in which more than half the animals failed to ovulate after GnRH treatment. However, there were no differences in the number of ovulation sites (4-7 per ovulating female) or eggs recovered (2-5 per ovulating female) among the treatment groups, except for females treated with 15 iu PMSG and inseminated $41-42 \mathrm{~h}$ after $2.5 \mathrm{mg} \mathrm{LH}$ treatment in which only I-2 eggs per ovulating female were recovered. There were also smaller numbers of follicles $>2 \mathrm{~mm}$ remaining for females treated with 10 iu PMSG and inseminated 26-4I h after $\mathrm{GnRH}$ compared with any of the 15 iu PMSG-treated groups $(P<0.05)$.

At best, 1-2 fertilized eggs or embryos per female were recovered after IUAI of animals primed with 15 iu PMSG and then induced to ovulate with either $\mathrm{GnRH}$ or $4 \mathrm{mg} \mathrm{LH}$. There was no difference in any of the criteria evaluated for possums inseminated either before or after the expected time of ovulation in these groups. Sperm remnants in the egg cytoplasm were not found in any of the two-cell or four-cell embryos but were identified in the fertilized eggs (Fig. 3). Fertility of females 


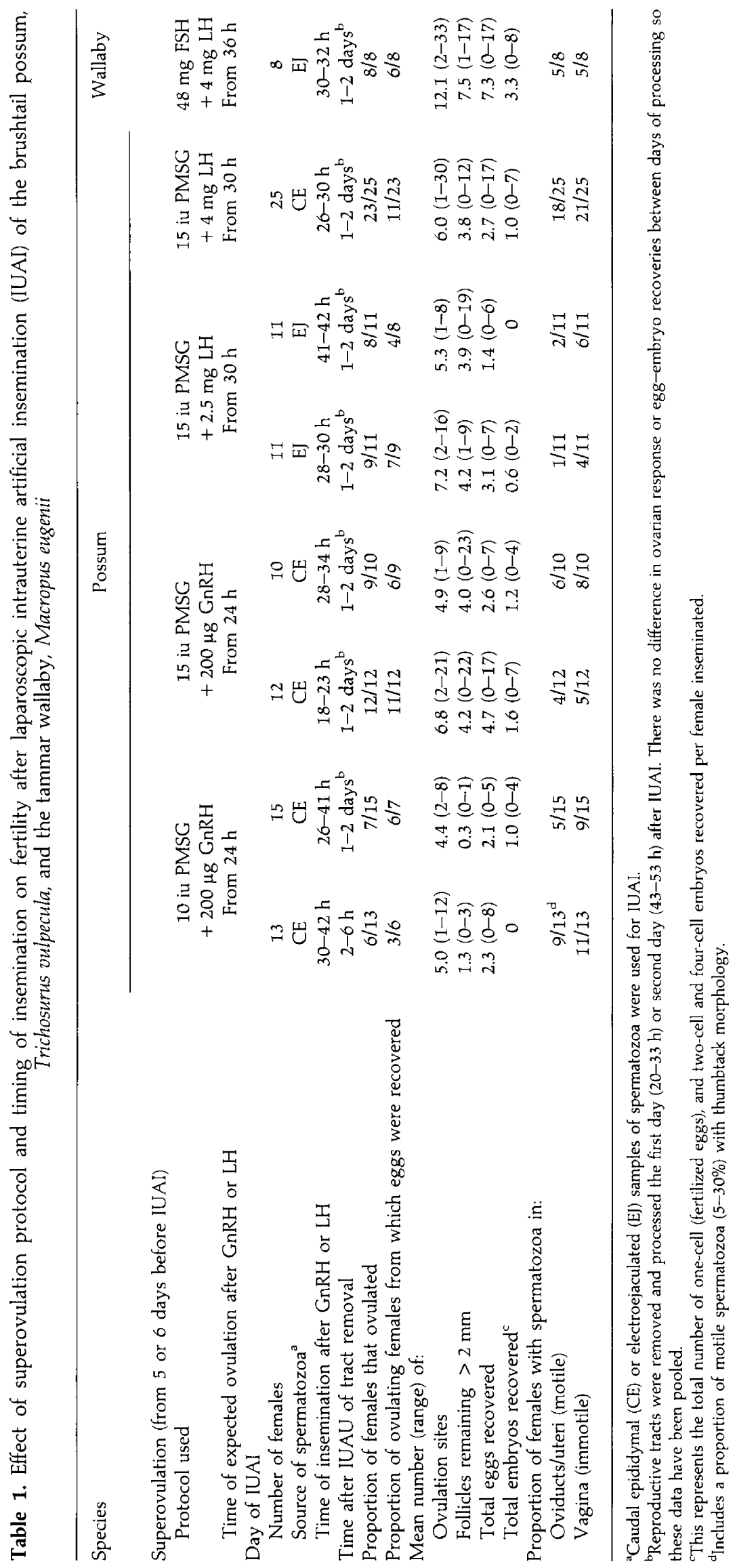



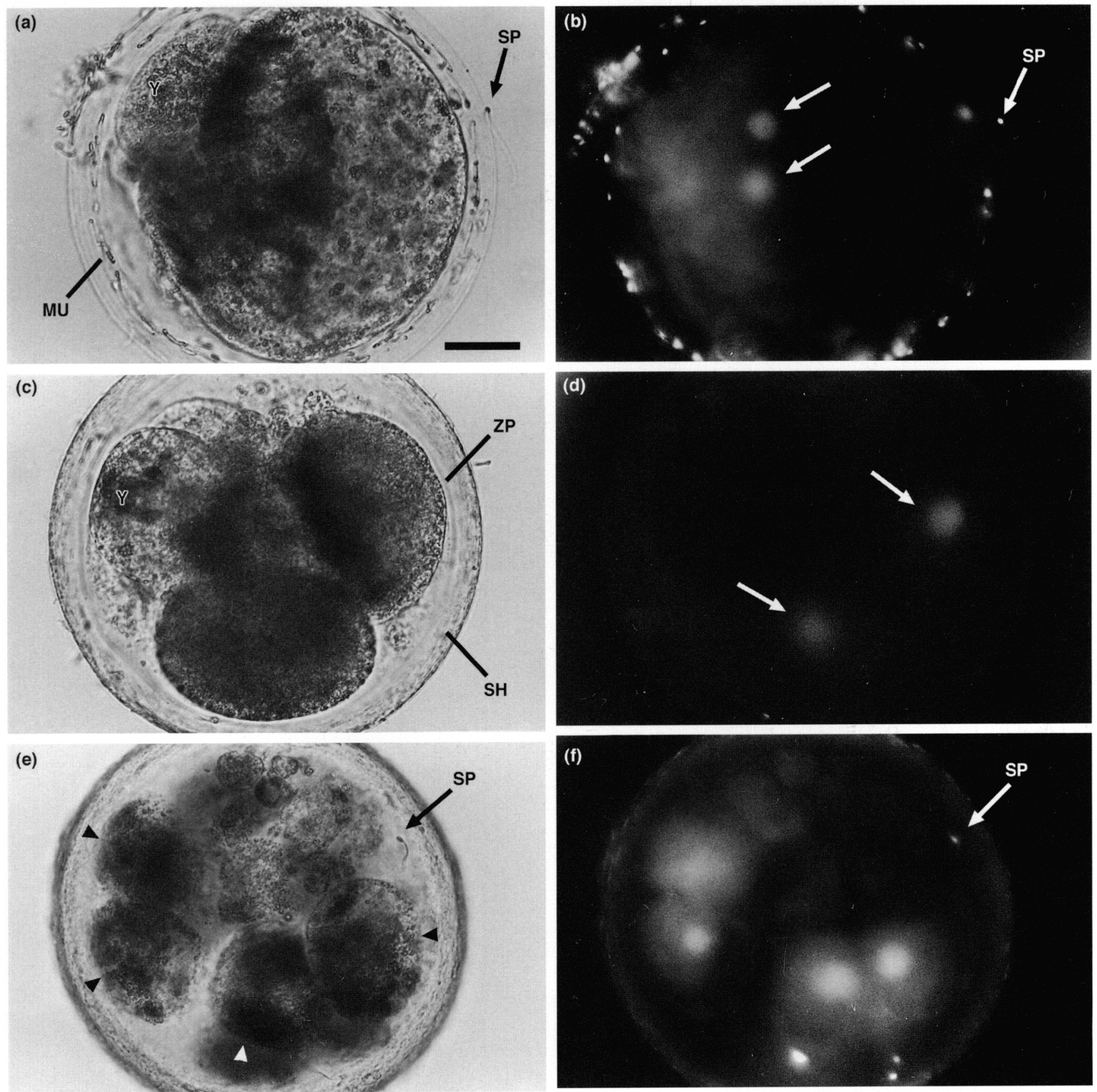

Fig. 1. Paired Hoffman modulation contrast and fluorescent micrographs of brushtail possum (Trichesime vitpectili) embryos stained with the DNA-specific dye Hoechst 33342. (a,b) The two-cell embryo that has just cleaved was recovered from the left oviduct $24 \mathrm{~h}$ after artificial insemination into the uterus (IUA). Yolk' (Y) material has been extruded into the perivitelline space in (a) and numerous spermatozoa (SP) are trapped in the mucoid (MU) layer. DNA is packaged in the nucleus of the sperm head; spermatozoa therefore appear as fluorescent dots around the perimeter of the egg in (b). The round fluorescent bodies inside the embryo (arrows) represent the nuclei of the two cells. (c,d) Later stage two-cell embryo recovered from the right uterus $25 \mathrm{~h}$ after IUAI. 'Yolk' material, zona pellucida (ZP) and the shell (SH) membrane are prominent in (c). Fluorescent nuclei of the two cells are indicated (arrows) in (d). (e,f) Four-cell embryo recovered from the left uterus $47 \mathrm{~h}$ after IUAI. Arrowheads indicate the location of the four cells in (e) as confirmed by the fluorescent staining of the nuclei in $(\mathrm{f})$. The smaller fluorescent bodies at the perimeter of the embryo are spermatozoa trapped in the mucoid layer. Scale bar represents $50 \mu \mathrm{m}$.

primed with 15 iu PMSG could be achieved with ejaculated spermatozoa if inseminations were performed $28-30 \mathrm{~h}$ after $2.5 \mathrm{mg}$ LH treatment, although insemination $41-42 \mathrm{~h}$ after treatment yielded no embryos. For females treated with $10 \mathrm{iu}$ PMSG and then GnRH, no embryos were recovered from animals examined $2-6 \mathrm{~h}$ after IUAI, but for those examined I-2 days later, one embryo per female was recovered.

Wallaby. Recruitment and development of follicles was achieved after priming females with $\mathrm{FSH}$, and ovulation was 

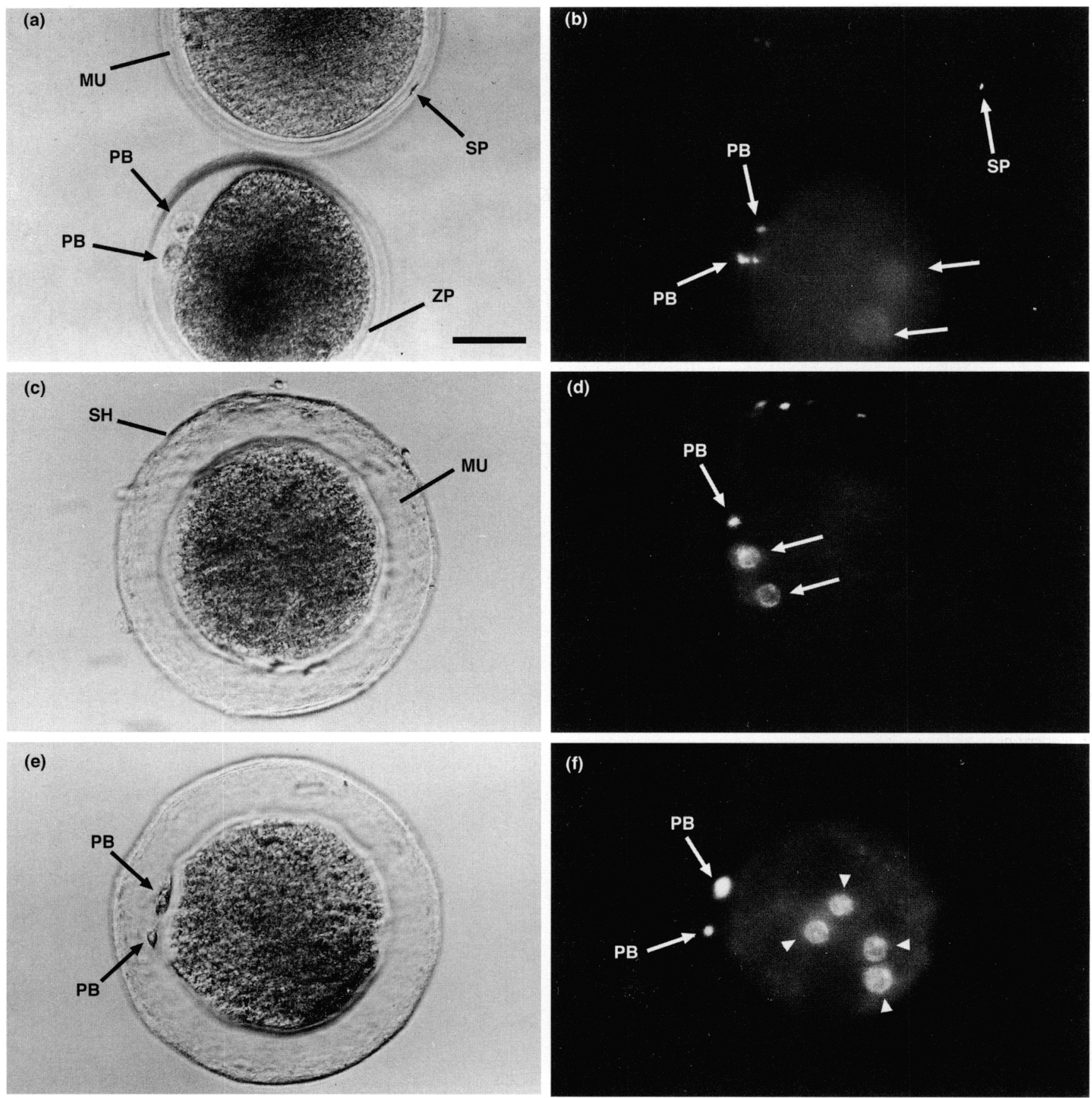

Fig. 2. Paired Hoffman modulation contrast and fluorescent micrographs of tammar wallaby (Mncropus eugenii) embryos stained with the DNA-specific dye Hoechst 33342. (a,b) Eggs recovered from the right oviduct $25 \mathrm{~h}$ after artificial insemination into the uterus (IUAI), but only the lower one is fertilized. Mucoid (MU) layer is thin and zona pellucida (ZP) and both polar bodies (PB) are prominent in (a). A single spermatozoon (SP) is trapped in the mucoid of the unfertilized egg. The fluorescent nuclei of the polar bodies and spermatozoa are visible in (b). The two weakly fluorescent rounded bodies (arrows) inside the fertilized egg represent male and female pronuclei. (c,d) Two-cell embryo recovered from the left uterus $50 \mathrm{~h}$ after IUAI. The mucoid layer is much thicker and bounded by a shell (SH) membrane in (c). Fluorescent nuclei of the two cells are indicated (arrows) in (d) and a polar body is prominent above these. The smaller fluorescent bodies at the perimeter of the embryo are spermatozoa trapped in the mucoid layer which are not sharply focussed in (c). (e,f) Four-cell cmbryo recovered from the left uterus of the same animal as in (c,d). The two polar bodies are prominent in (e) and these are fluorescently stained in ( $\mathrm{f})$. Fluorescent nuclei of the four cells are indicated (arrowheads), although these cannot be clearly delineated in (e). Scale bar represents $50 \mu \mathrm{m}$.

induced by LH. After IUAI with ejaculated spermatozoa $4-6 \mathrm{~h}$ before the onset of ovulation, approximately 12 ovulation sites per female were observed but a further 7-8 large follicles per female failed to ovulate. At least seven eggs, including three or four fertilized eggs or embryos, were recovered per female treated. 


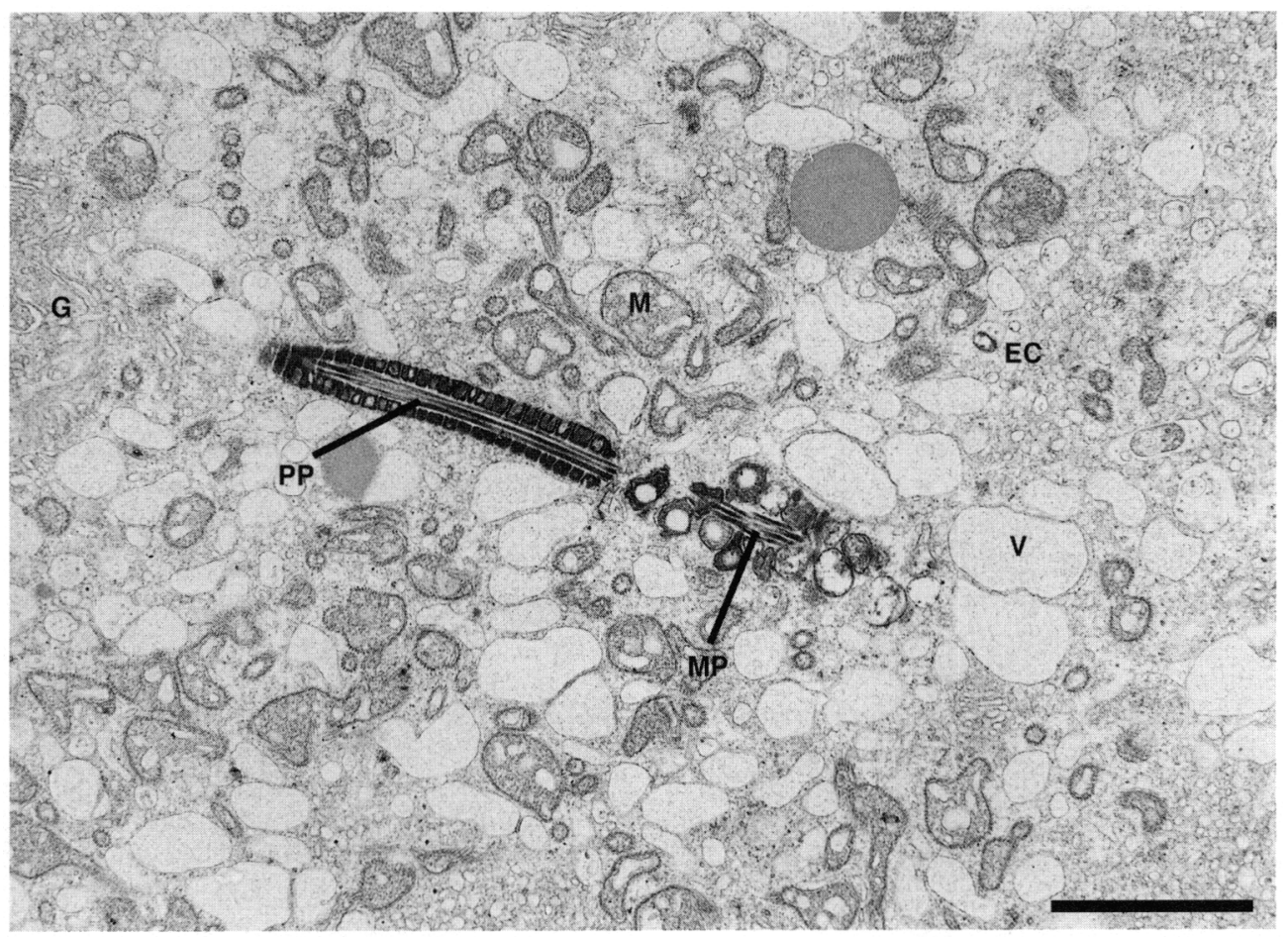

Fig. 3. Electron photomicrograph of a fertilized egg recovered from the left oviduct of a brushtail possum (Trichosurus vulpecula) $25 \mathrm{~h}$ after artificial insemination into the uterus. Fertilization is confirmed by the presence of sperm mid-piece (MP) and principal-piece (PP) remnants in the egg cytoplasm (EC). The egg cytoplasm contains Golgi $(G)$, numerous mitochondria (M) and vesicles (V). Scale bar represents $2.5 \mu \mathrm{m}$.

\section{Recovery of spermatozoa}

Spermatozoa were recovered over the entire $2-53 \mathrm{~h}$ after IUAI from the oviduct or from uterine flushes from at least a third of possums and wallabies inseminated after all treatments, except for the possums treated with PMSG-LH (2.5 mg). After this treatment, spermatozoa were recovered from only 9-18\% of animals inseminated (Table 1). Spermatozoa from the flushes were motile with a progressive motility score of $3-5$ on a $0-5$ motility scale (Rodger et al., 1991). For animals treated with 10 iu PMSG-GnRH and examined 2-6 h after IUAI, a small proportion $(5-30 \%)$ of highly motile spermatozoa with T-shape or thumbtack morphology (Breed, 1994) were recovered from the oviducts. Although inseminations were performed directly into the uteri, spermatozoa were recovered in the vaginal smears of $36-85 \%$ of possums and wallabies but these spermatozoa were immotile.

\section{Discussion}

This study is the first to report the recovery of fertilized eggs and embryos after superovulation and artificial insemination in any marsupial species. Evidence of sperm tail remnants in the cytoplasm of the possum egg indicated that the embryos recovered were fertilized and not activated parthenogenetically. Fertilized eggs were first detected at $20 \mathrm{~h}$ after IUAI, although earlier frames (from 6 to $20 \mathrm{~h}$ ) were not examined. Overall, both the location and developmental status of possum and wallaby embryos retrieved after IUAI were consistent with that observed after fertilization in naturally mated females (Tyndale-Biscoe and Renfree, 1987; Renfree and Lewis, 1996).

At least $90 \%$ of possums ovulated after treatment with 15 iu PMSG followed 3 days later by four doses of $50 \mu \mathrm{g}$ GnRH (at intervals of $90 \mathrm{~min}$ ). Over half of the animals primed with $10 \mathrm{iu}$ PMSG failed to ovulate and there was recruitment and development of fewer follicles for those animals that did ovulate (10 iu PMSG: 4-5; and 15 iu PMSG: 9-11 ovulation sites and remaining large follicles per female, respectively). These doses of PMSG and GnRH are higher than those used for optimal superovulation of Australian brushtail possums (Rodger and Mate, 1988) but were probably necessary to compensate for the higher body weights of the New Zealand possums used in this study ( $>2 \mathrm{~kg}$ compared with $1.5-2.0 \mathrm{~kg}$ ). Induction of ovulation could also be achieved with a single dose of LH in both cyclic and non-cyclic females, but a slightly higher proportion of animals ovulated if $4 \mathrm{mg}$ rather than $2.5 \mathrm{mg} \mathrm{LH}$ was used. Superovulation of tammar wallabies was successfully achieved using a recently developed FSH-LH protocol (Molinia et al., in press), and this is currently being examined in the possum to increase the number of ovulations, oocytes and embryos recovered after IUAI.

The low embryo yields reported in this study are probably due, in part, to the failure of ovulation or egg transport to the oviduct, or both, after the laparoscopy. Although most possums ovulated after IUAI, the number of ovulation sites was lower than the 9-10 per female reported for superovulated possums that had not been inseminated (Glazier and Molinia, 1998). Furthermore, for all groups of animals, the numbers of eggs recovered were always lower than the number of 
ovulation sites, and no eggs were recovered from up to half of the animals that had apparently ovulated after IUAI. Laparoscopic IUAI after exogenous gonadotrophin treatment reduces ovulation in domestic cats (Howard et al., 1992) and tigers (Donoghue et al., 1996) and compromises egg recovery in sheep (Evans, 1988). These effects may be related to the endocrine status of the animal after hormone manipulation and laparoscopy and this is currently being examined for the possum and wallaby. However, preliminary results indicate that much larger numbers of eggs and embryos may be recovered than for IUAI when PMSG-LH-primed possums are inseminated into the vaginal cul-de-sac $18 \mathrm{~h}$ or $24 \mathrm{~h}$ before the onset of ovulation $(6 \mathrm{~h}$ or $12 \mathrm{~h}$ after LH; F. C. Molinia, M. K. Jungnickel and J. C. Rodger, unpublished).

Fertilized eggs and two- and four-cell embryos could be retrieved simultaneously from a single possum or wallaby after IUAI. This finding suggests that ovulation of multiple follicles and concomitant fertilization is occurring over several hours or that the resultant embryos are developing at different rates in vivo. Fertilization occurs in the narrow time band between ovulation and mucoid deposition (Rodger, 1994) and it has been demonstrated that superovulation of possums (A. M. Glazier, unpublished) and wallabies (Molinia et al., in press) results in the ovulation of multiple oocytes over several hours. However, at least half of the eggs recovered from superovulated-IUAI-treated animals in this study were not fertilized. This is probably due to the asynchrony between ovulation and the arrival of spermatozoa at the site of fertilization, which has also been reported for domestic cats and wild felids after gonadotrophin-induced ovulation and IUAI (Donoghue et al., 1996; Roth et al., 1997).

On the basis of preliminary investigations in the present study, most embryos would probably have degenerated if left to develop in vivo for $>4$ days after IUAI. In the normally polyovular dasyurids, about a quarter of eggs fail to fertilize at all and the number of embryos that continue development does not greatly exceed the number of teats (Tyndale-Biscoe and Renfree, 1987). Both the possum and wallaby are monovular and it is likely that the hormonal milieu of superovulated animals may be inadequate to sustain development of multiple embryos. Embryo transfer to surrogate females, which has been achieved in tammar wallabies (Renfree and Tyndale-Biscoe, 1978), is required to assess the capability of the multiple embryos generated from superovulation-artificial insemination to develop to term.

Marsupial-like eutherian spermatozoa undergo an obligatory prefertilization maturational event called capacitation, but this is poorly understood (Mate and Rodger, 1996). Recent work with the dasyurid Sminthopsis crassicaudata has demonstrated the presence of motile spermatozoa in the isthmus of the oviduct with T-shape or thumbtack morphology, which is thought to be an indicator of capacitation (Breed, 1994). Motile spermatozoa with thumbtack morphology were recovered from the oviducts of inseminated possums $2-6 \mathrm{~h}$ after IUAI, which confirms that the oviduct is probably the site where capacitation occurs in marsupials as it is in eutherian mammals (Bedford, 1991).

Fertile conceptions were achieved with both epididymal and ejaculated spermatozoa using a uterine route of insemination. However, results from this study do not establish conclusively whether there is a difference in fertility between ejaculated and epididymal spermatozoa. Intravaginal insemination, which more closely mimics natural mating, is currently being used to determine this and to examine the role of the female reproductive tract in preparing spermatozoa for fertilization.

The successful development of superovulation and artificial insemination has enormous implications for marsupial biology. Potentially, it is an invaluable tool to aid basic research on marsupial gamete function, capacitation, sperm transport, fertilization and the pre-implantation embryo. Information on these processes will be important for the development of fertilitybased biocontrol of pest marsupial populations. Furthermore, in conjunction with sperm-embryo freezing and embryo transfer, it will aid the development of artificial breeding strategies for the management of captive marsupial communities and the conservation of rare or endangered species.

This study was undertaken with the financial assistance of the Australian Cooperative Research Centre Program, the Australian Research Council and the New Zealand Ministry of Agriculture and Fisheries. The authors thank L. Meikle and the staff of the Landcare Research Animal Facility at Rangiora for trapping and handling of possums in New Zealand. They thank S. Jolly and R. Gentle for veterinary advice and J. Duckworth, K. Mate, M. Jungnickel and L. Markham for their skilled technical assistance. Special thanks go to A. Harman for the electron microscopy work and M. Lin and $\mathrm{T}$. Fletcher for their helpful advice and comments on the manuscript.

\section{References}

Bedford JM (1991) The coevolution of mammalian gametes. In A Comparative Overview of Mammalian Fertilization Vol 2 pp 379-569 Eds BS Dunbar and MG O'Rand. Plenum Press, New York

Breed WG (1994) How does sperm meet egg? - in a marsupial. In Marsupial Reproduction: Gametes, Fertilization and Early Development. Reproduction Fertility and Development 6 485-506

Donoghue AM, Byers AP, Johnston LA, Armstrong DL and Wildt DE (1996) Timing of ovulation after gonadotrophin induction and its importance to successful intrauterine insemination in the tiger (Panthera tigris) Journal of Reproduction and Fertility 107 53-58

Evans G (I988) Current topics in artificial insemination of sheep Australian Journal of Biological Sciences 41 103-116

Evans G and Maxwell WMC (1987) Salamon's Artificial Insemination of Sheep and Goats Butterworths, Sydney

Glazier AM and Molinia FC (1998) An improved method of superovulation in the monovulatory brushtail possum (Trichosurus vulpecula) using PMSG/LH Journal of Reproduction and Fertility (in press)

Greenwald GS and Terranova PF (1988) Follicle selection and its control. In The Physiology of Reproduction Vol 1 pp 387-445 Eds E Knobil and JD Neill. Raven Press, New York

Hayman DL and Rodger JC (1990) Meiosis in male and female Trichosurus vulpecula (Marsupialia) Heredity $64251-254$

Hinds LA, Fletcher TP and Rodger JC (1996) Hormones of oestrus and ovulation and their manipulation in marsupials. In Marsupial Gametes and Embryos. Reproduction Fertility and Development 8 661-672

Howard JG, Barone MA, Donoghue AM and Wildt DE (1992) The effect of pre-ovulatory anaesthesia on ovulation in laparoscopically inseminated domestic cats Journal of Reproduction and Fertility 96 175-186

Mate KE and Rodger JC (1991) Stability of the acrosome of the brush-tailed possum (Trichosurus oulpecula) and tammar wallaby (Macropus eugenii) in vitro and after exposure to conditions and agents known to cause capacitation or acrosome reaction of eutherian spermatozoa Journal of Reproduction and Fertility $9141-48$

Mate KE, Giles I and Rodger JC (1992) Evidence that cortical granule formation is a periovulatory event in marsupials Journal of Reproduction and Fertility 95 $719-728$ 
Mate KE and Rodger JC (1996) Capacitation and the acrosome reaction in marsupial spermatozoa. In Marsupial Gametes and Embryos. Reproduction Fertility and Development 8 595-603

Molinia FC, Gibson RJ, Smedley MA and Rodger JC Further observations of the ovarian response of the tammar wallaby, Macropus eugenii, to exogenous gonadotrophins: an improved method for superovulation using FSH/LH. In Reproduction in Wildlife Species. Animal Reproduction Science (in press)

Renfree MB and Lewis AMcD (1996) Cleavage in vivo and in vitro in the marsupial Macropus eugenii. In Marsupial Gametes and Embryos. Reproduction Fertility and Development 8 725-742

Renfree MB and Tyndale-Biscoe CH (1978) Manipulation of marsupial embryos and pouch young. In Methods in Mammalian Reproduction pp 307-331 Ed. JC Daniel. Academic Press, New York

Rodger JC (1990) Prospects for the artificial manipulation of marsupial reproduction and its application in research and conservation Australian Journal of Zoology 37 249-258

Rodger JC (1994) Prefertilization gamete maturation events in marsupials. In Marsupial Reproduction: Gametes, Fertilization and Early Development. Reproduction Fertility and Development 6 473-483

Rodger JC and Mate KE (1988) A PMSG/GnRH method for the superovulation of the monovulatory brush-tailed possum (Trichosurus vulpecula) Journal of Reproduction and Fertility $\mathbf{8 3}$ 885-89I

Rodger JC and White IG (1978) The collection, handling and some properties of marsupial semen. In Artificial Breeding of Non-Domesticated Animals pp 289-301 Ed. PF Watson Symposium of the Zoological Society of London 43 Academic Press, London

Rodger JC, Cousins SJ and Mate KE (1991) A simple glycerol-based freezing protocol for the semen of a marsupial Trichosurus vulpecula, the common brushtail possum Reproduction Fertility and Development 3 119-125

Rodger JC, Cousins SJ, Mate KE and Hinds LA (1993) Ovarian function and its manipulation in the tammar wallaby, Macropus engenii. Reproduction Fertility and Development 5 27-38

Roth TL, Wolfe BA, Long JA, Howard JG and Wildt DE (1997) Effects of equine chorionic gonadotrophin, human chorionic gonadotrophin, and laparoscopic artificial insemination on embryo, endocrine, and luteal characteristics in the domestic cat Biology of Reproduction 57 165-171

Sistina Y, Lin M, Mate KE and Rodger JC (1993) Induction of the marsupial acrosome reaction in vitro by treatment with diacylglycerols Journal of Reproduction and Fertility 99 335-341

Tyndale-Biscoe CH and Renfree MB (1987) Reproductive Physiology of Marsupials Cambridge University Press, Cambridge

Wildt D, Pukazhenthi B, Brown J, Monfort S, Howard J and Roth T (1995) Spermatology for understanding, managing and conserving rare species Reproduction Fertility and Development 7 811-824

Zamboni L and De Martino C (1967) Buffered picric acid-formaldehyde: a new, rapid fixative for electron microscopy Journal of Cell Biology $\mathbf{3 5}$ $148 \mathrm{a}$ 